This document is PUBLICLY RELEASABLE

Umary R. Hale, ANL
Authorizing 8 fificial
Date $8-17-09$

February 1974
This report was prepared as an account of work sponsoted by the Unted States Government. Neither the Unted States nor the Unted States Atomic Energy Commission, nor any of their employees, nor any of their contractors, subcontractors, or ther employees, makes any warranty, express or implied, or assumes any legal liability or responsibility for the accuracy, comm legal liability or responsibility for the accuracy, com-
pleteness or usefulness of any information, apparatus, pleteness or usefulness of any information, apparatus,
product or process disclosed, or represents that its use woulu not infringe privately owned rigits.

* Now in Monroeton, Pennsylvania

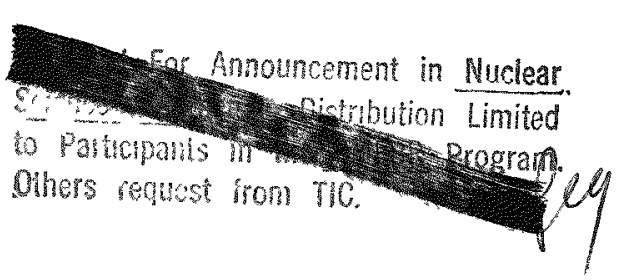




\section{DISCLAIMER}

This report was prepared as an account of work sponsored by an agency of the United States Government. Neither the United States Government nor any agency Thereof, nor any of their employees, makes any warranty, express or implied, or assumes any legal liability or responsibility for the accuracy, completeness, or usefulness of any information, apparatus, product, or process disclosed, or represents that its use would not infringe privately owned rights. Reference herein to any specific commercial product, process, or service by trade name, trademark, manufacturer, or otherwise does not necessarily constitute or imply its endorsement, recommendation, or favoring by the United States Government or any agency thereof. The views and opinions of authors expressed herein do not necessarily state or reflect those of the United States Government or any agency thereof. 


\section{DISCLAIMER}

Portions of this document may be illegible in electronic image products. Images are produced from the best available original document. 


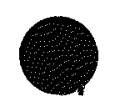

. 
TABLE OF CONTENTS

$\underline{\text { Page }}$

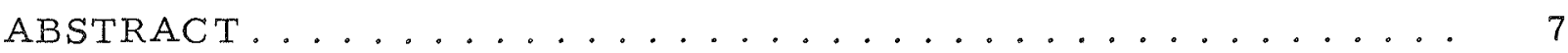

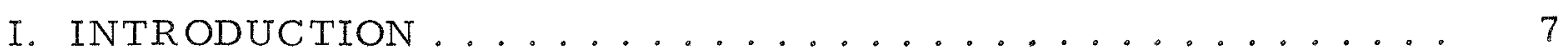

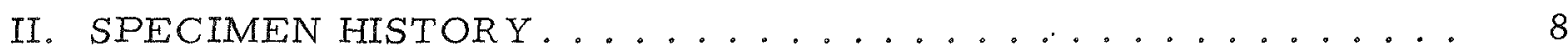

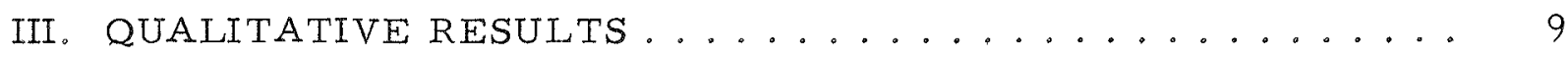

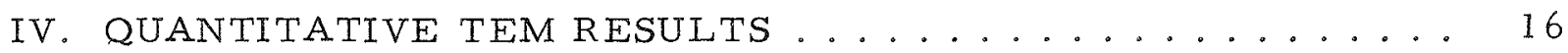

V. FISSION-GAS RETENTION BY LASER SAMPLING . . . . . 18

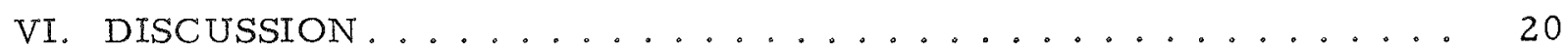

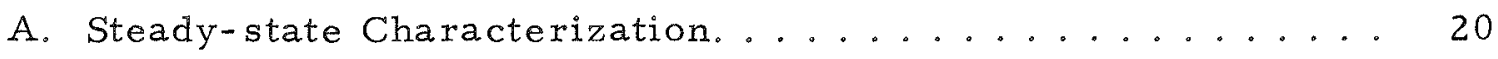

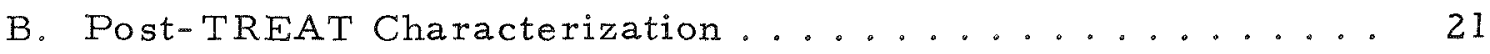

C. Transient-induced Fuel Swelling.............. 23

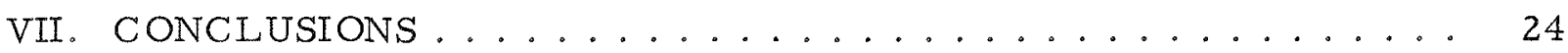

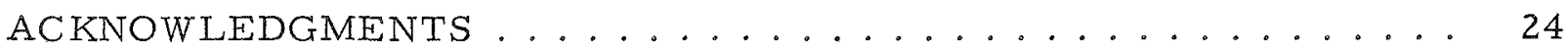

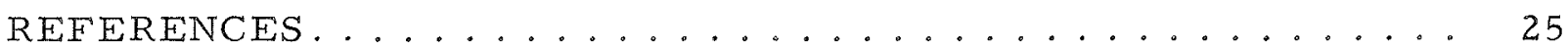


LIST OF FIGURES

No.

Title

Page

1. Calculated Peak Steady-state Temperature as a Function of

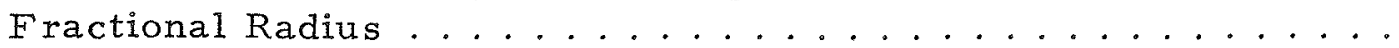

2. COBRA-III Calculated Temperature as a Function of Transient Time at Several Radial Positions ................

3. Calculated Peak Transient Temperature as a Function of Fractional Radius at $10.2 \mathrm{sec} \ldots \ldots \ldots \ldots$

4. Midplane Cross Sections from Sibling and Transient-

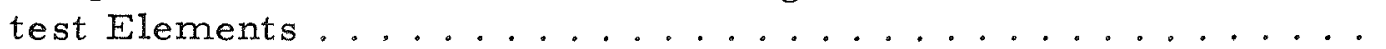

5. Microstructure from Unrestructured Region of Steady-state

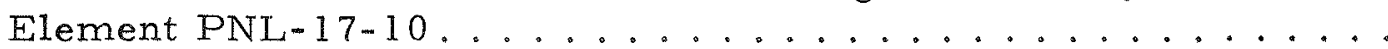

6. Microstructure from Equiaxed Region of Steady-state

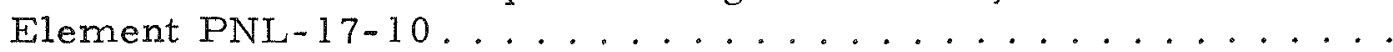

7. Microstructure at Equiaxed-columnar-region Boundary of Steady-state Element PNL-17-10 ..............

8. Microstructure from Columnar Region of Steady-state

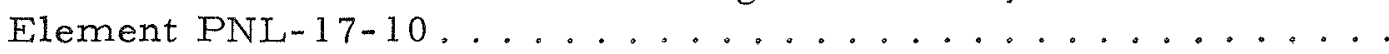

9. Microstructure from Unrestructured Region of Transient-test

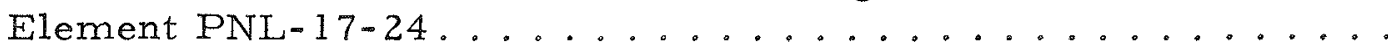

10. Microstructure from Equiaxed Region of Transient-test

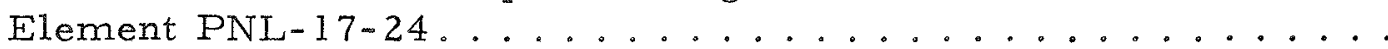

11. Intragranular Surface from Columnar Region of Transient-test

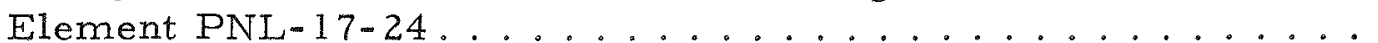

12. Microstructures from Columnar Region of Transient-test

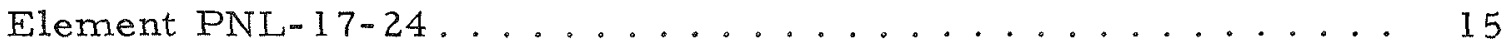

13. Grain-boundary Bubble-size Distribution at $r / r_{0}=0.40 \ldots 16$

14. Grain-boundary Bubble-size Distribution at $r / r_{0}=0.30 \ldots 16$

15. Intragranular Bubble Density as a Function of Fractional Radius . 17

16. Comparison of Laser-sampling Data for PNL-17-24 and

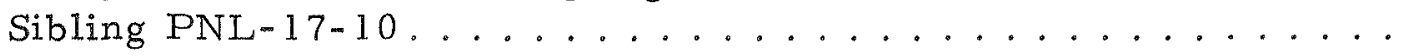




\section{LIST OF TABLES}

No.

I. Grain Size and Structure as a Function of Radius......... 10

II. Grain-boundary Fission-gas Atom Densities........... 18

III. Intragranular Bubble Densities. ............... 18

IV. Midplane Gas Contents in PNL-17-10 and $-24 \ldots \ldots 19$

V. Calculated Fission-gas Locations............... 20 


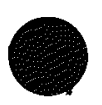

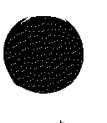




\title{
FISSION-GAS BEHAVIOR DURING \\ A MILD OVER-POWER TRANSIENT
}

by

D. Stahl and T. J. Patrician

\begin{abstract}
Fission-gas morphology and retention were determined by both replica electron fractography and laser sampling for two fast-reactor elements, one of which was subsequently transient-tested in TREAT. Both mixed-oxide fuel elements were irradiated in EBR-II at a peak power level of $\sim 10 \mathrm{~kW} / \mathrm{ft}$ to an average burnup of $\sim 3.2$ at. $\%$. The H3 sodium-loop transient test was subjected to a short, flattop power input followed by a mild ( $50 \phi$ to $\$ 1 / \mathrm{sec}$ ) over-power ramp in TREAT.

The TREAT transient caused additional fission gas to precipitate from solution or to coalesce from smaller unresolved bubbles. The degree of production and migration of these bubbles was dependent on the temperature and the temperature gradient. The density of $\sim 650-\AA$ intragranular bubbles increased by about an order of magnitude in the region of the equiaxed and unrestructured zone boundary.

Laser sampling revealed that most of the fission gas retained in the fuel during steady-state operation was located in the unrestructured region and the cooler part of the equiaxed region. The additional release of $\sim 8.7 \%$ of the gas during the transient was from these regions, principally through additional thermal-shock-induced cracks.
\end{abstract}

\section{INTRODUCTION}

The presence of inert fission gases, xenon and krypton, in oxide reactor fuels plays a significant role in the swelling behavior of these fuels. Under thermodynamic equilibrium, both xenon and krypton have extremely low solubilities in oxide reactor fuels (enriched $\mathrm{UO}_{2}$ or mixed oxides of $\mathrm{UO}_{2}-\mathrm{PuO}_{2}$ ) ${ }_{0}^{1,2}$ However, the re-solution of these gases as a result of interaction with fission fragments during the lifetime of the fuel may result in a much higher effective fission-gas solubility ${ }^{3,4}$ Since fuel swelling during normal and off-normal reactor conditions depends on the size of fission-gas bubbles and the rate of bubble coalescence, it is paramount to determine the distribution and size of fission-gas bubbles in the fuel, both within the grains and at grain boundaries. 
It is foreseeable that, during Liquid Metal Fast Breeder Reactor ( $L M F B R$ ) operation, a transient may occur that will result in the rapid heating of the fuel to temperatures in the vicinity of the fuel solidus. Among the many adverse effects that such a transient would have on an LMFBR is the possibility of a cladding failure caused by the rapid precipitation of large quantities of fission gas, resulting in virtual instantaneous fuel swelling. The availability of fission gas for precipitation during a transient is substantial. For an enriched $\mathrm{UO}_{2}$ fuel irradiated in EBR-II, Pati et a1. ${ }^{5}$ have shown that, for temperatures to $\sim 1300^{\circ} \mathrm{C}, \sim 80 \%$ of the fission gas produced is retained in solution, or at least in bubbles too small to be resolved by Transmission Electron Microscopy (TEM). To determine the effects of a $50 \phi$ to $\$ 1 / \mathrm{sec}$ transient on fission-gas behavior, fission-gas bubbles in a $\mathrm{UO}_{2}-25$ wt $\% \mathrm{PuO}_{2}$ fuel subjected to a transient in TREAT were compared with bubbles in a similar fuel that had not undergone a transient.

\section{SPECIMEN HISTORY}

The characterization of the radial distribution and size of fission-gas bubbles was determined for equivalent cross sections of two mixed-oxide fuel elements (PNL-17-10 and -24) that were irradiated in the EBR-II subassembly XX02 to $\sim 3.2$ at. \% burnup at a peak power level of $\sim 10.3 \mathrm{~kW} / \mathrm{ft}$. Element PNL-17-24 was subsequently tested under transient conditions in the TREAT reactor. The sibling element (PNL-17-10) was assumed to be identical to PNL-17-24 after irradiation in the EBR-II; therefore, any differences in gas -bubble morphology between the two elements were assumed to result from the transient test.

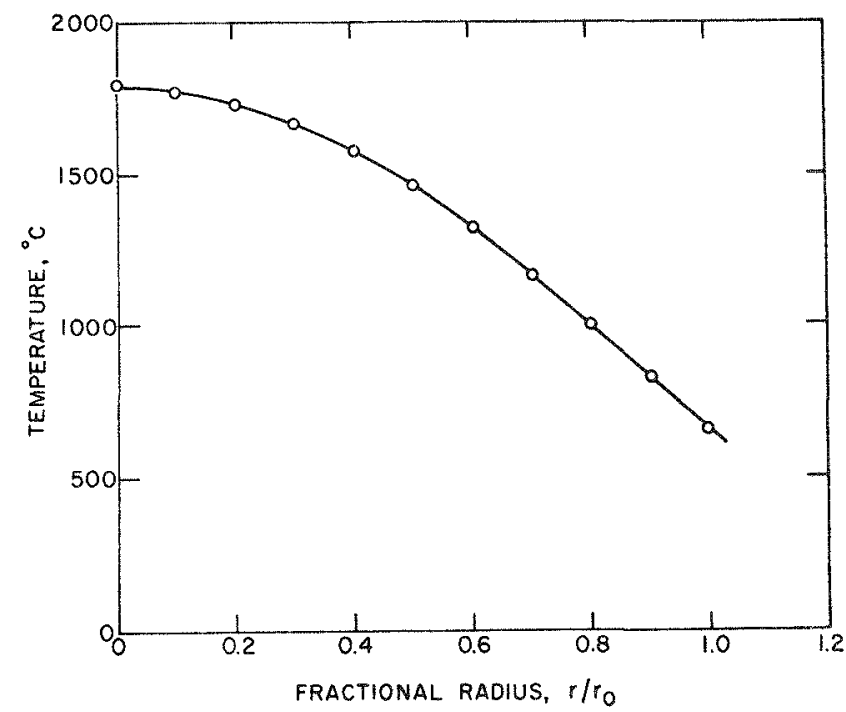

Fig. 1

Calculated Peak Steady-state Temperature as a Function of Fractional Radius. Neg. No. MSD-59633.
The fuel used in the subassembly was pressed and sintered into nominally $0.493-\mathrm{cm}$-dia pellets containing 75 wt $\% \mathrm{UO}_{2}(65.3$ wt $\%$ enriched ${ }^{235} \mathrm{U}$ ) and $25 \mathrm{wt} \% \mathrm{PuO}_{2}$ $\left(88.8\right.$ wt \% enriched $\left.{ }^{239} \mathrm{Fu}+{ }^{241} \mathrm{Pu}\right){ }^{6}$ The average density of the fuel in PNL-17-10 was $93.25 \%$ of theoretical and had an oxygen-to-metal (O/M) ratio of 1.964: PNL-17-24 had an average theoretical density of $93.18 \%$ with an $O / M$ ratio of 1.958 . The smeared density for both elements was $88.98 \%$ of theoretical.

For both elements, a radial profile of temperature for the peak power position before the end of irradiation in the EBR-II was calculated using the method of Meyer and Buescher. ${ }^{7}$ The profile given in Fig. 1 
was calculated for the following conditions: linear power, $10.3 \mathrm{~kW} / \mathrm{ft}$; fabricated density, $93.3 \% \mathrm{TD}$; fuel-surface temperature, $633^{\circ} \mathrm{C}$; fuel-surface radius, $0.246 \mathrm{~cm}$; and central-void radius, $0.0013 \mathrm{~cm}$.

The transient test (Test $\mathrm{H} 3$ ) on PNL-17-24 is described in detail by Rothman et al. ${ }^{8}$ Test H3 was designed to simulate an over-power transient equivalent to a $50 \phi$ to $\$ 1 / \mathrm{sec}$ reactivity insertion rate for a prototypic $L M F B R$ element that would bring the mixed oxide just to the solidus temperature. Figure 2 shows the time versus temperature plot during $\mathrm{H} 3$ for several radial positions at the peak power cross section of element PNL-17-24. The maximum temperatures predicted during the transient occurred at 10.2 sec and are shown for various radial positions in Fig. 3. The maximum uncertainty in the calculated temperature at $10.2 \mathrm{sec}$ is +0 and $-100^{\circ} \mathrm{C}$. Inputs for Figs. 2 and 3 were calculated by Royl et al. 9

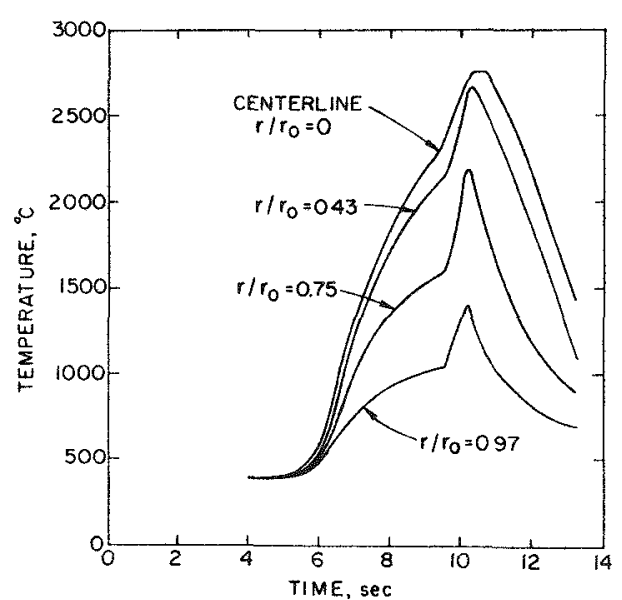

Fig. 2

COBRA-III Calculated Temperature as a Function of Transient Time at Several Radial Positions. Neg. No. MSD-59632.

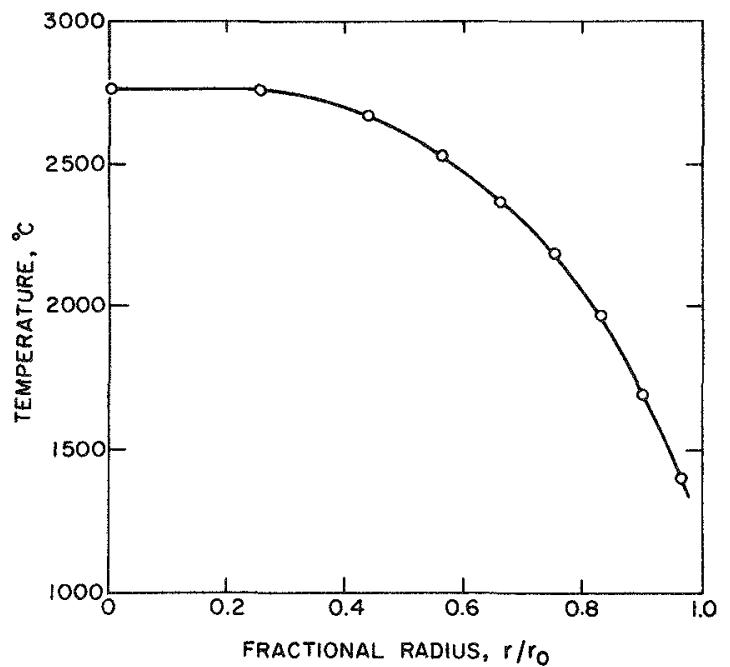

Fig. 3

Calculated Peak Transient Temperature as a Function of Fractional Radius at $10.2 \mathrm{sec}$. Neg. No. MSD-59634.

The Materials Science Division Alpha-Gamma Hot Cell personnel did the sectioning, mounting, polishing, and fracturing of the fuel elements from which the fracture replicas were prepared. Composite micrographs were made of the fractured surfaces so that, during examination by TEM, an accurate correlation of the electron micrographs to a radial position on the fuel element was possible. The fracture replicas for TEM examination were prepared using the method of Michels and Dragel. ${ }^{10}$ The carbon replicas were shadowed with Pt-20 wt \% Pd alloy.

\section{QUALITATIVE RESULTS}

Composite micrographs of midplane cross sections of elements PNL-1710 and -24 show that the grain structures are similar (Fig. 4). The areas near 
the cladding were composed of small, unrestructured grains. Away from the cladding toward the center of the fuel, the grain size increases to form a region of larger equiaxed grains over the middle half of both radii. The inner third of each radius was composed of columnar grains. Variations of structure and grain size with radial position are listed in Table I. From the se data and Fig. 4, it is apparent that the transient test had little effect on the grain size; that is, no additional restructuring took place.

In the unre structured region of PNL-17-10, the sibling element, from the fuel surface to $0.73 \mathrm{r} / \mathrm{r}_{\mathrm{O}}$ (where $\mathrm{r}$ is the distance from the center, and $\mathrm{r}_{\mathrm{O}}$ is the radius of the element), the fractures are intragranular (Fig. 5a) with a few small pores at the grain boundaries. Random fission-gas bubbles $\sim 650 \AA$ are visible on cleavage surfaces, as seen in Fig. 5b. In the restructured equiaxed region, about

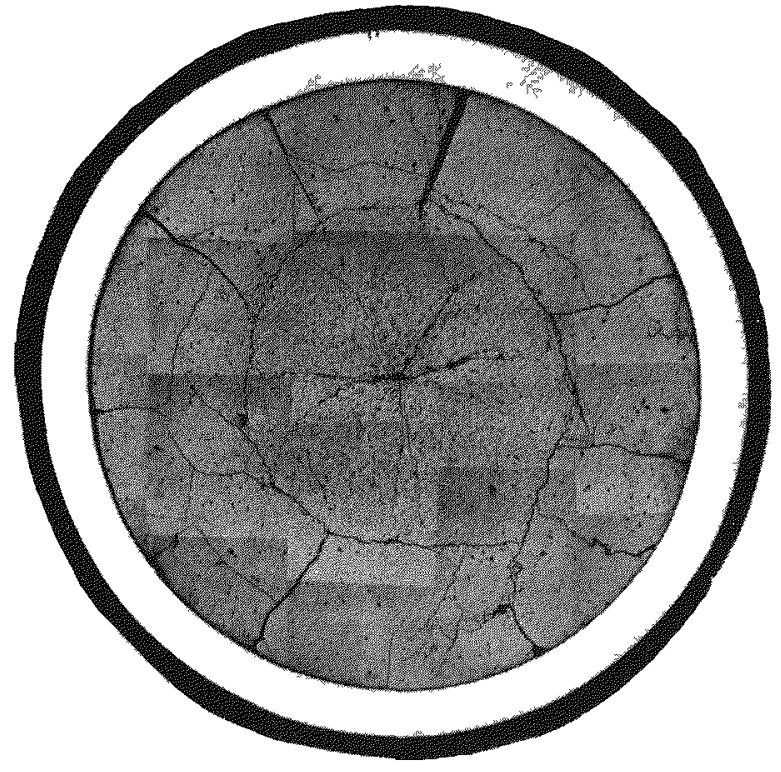

PNL-17-10 (Sibling)

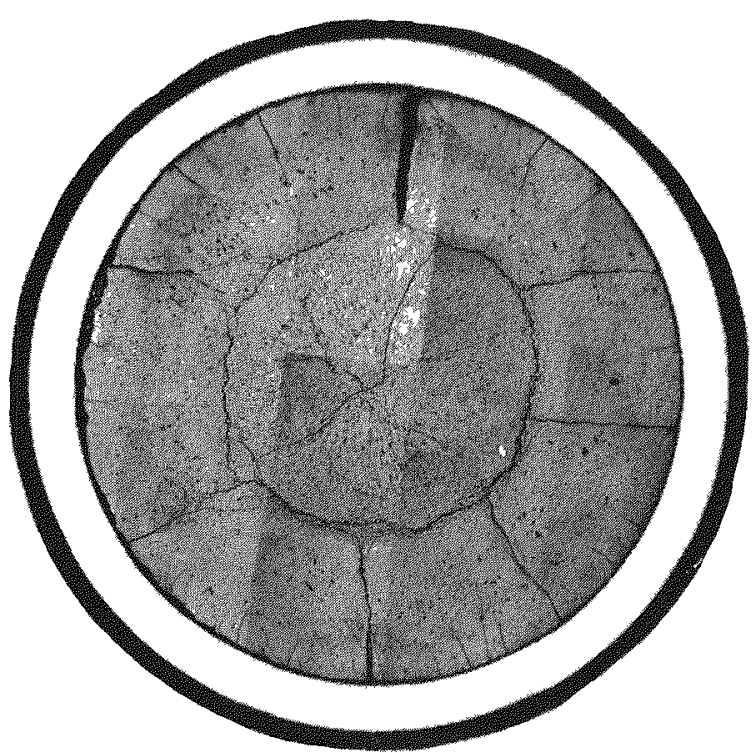

PNL-17-24 (Treat-tested)

Fig. 4. Midplane Cross Sections from Sibling and Transient-test Elements. Neg. No. MSD-164742.

TABLE I. Grain Size and Structure as a Function of Radius

\begin{tabular}{|c|c|c|c|c|}
\hline \multicolumn{2}{|c|}{$\begin{array}{c}\text { Average Grain Size, } \mu \mathrm{m} \\
\text { PNL-17-10 }\end{array}$} & \multirow{2}{*}{$\frac{\text { Range, } r / r_{0}}{0-0.1}$} & \multicolumn{2}{|c|}{$\begin{array}{c}\text { Average Grain Size, } \mu \mathrm{m} \\
\text { PNL-1 7-24 }\end{array}$} \\
\hline \multirow{4}{*}{$\begin{array}{l}\text { Columnar } \\
0.41-0.04\end{array}$} & 28.7 & & 22.9 & \multirow{4}{*}{$\begin{array}{l}\text { Columnax } \\
0.41-0.01\end{array}$} \\
\hline & 60.0 & $0.1-0.2$ & 52.1 & \\
\hline & 40.4 & $0.2-0.3$ & 45.9 & \\
\hline & 190 & $0.3 \sim 0.4$ & 31.4 & \\
\hline \multirow{4}{*}{$\begin{array}{l}\text { Equiaxed } \\
0.73-0.41\end{array}$} & 37.4 & $0.4-0.5$ & 29.7 & \multirow{4}{*}{$\begin{array}{l}\text { Equiaxed } \\
0.73-0.41\end{array}$} \\
\hline & 26.5 & $0.5-0.6$ & 31.2 & \\
\hline & 12.4 & $0.6-0.7$ & 20.2 & \\
\hline & 7.1 & $0.7-0.8$ & 105 & \\
\hline \multirow{2}{*}{$\begin{array}{c}\text { Unrestructured } \\
1.00-0.73\end{array}$} & 4.0 & $0.8-0.9$ & 6.6 & \multirow{2}{*}{$\begin{array}{c}\text { Unrestructured } \\
1.00\end{array}$} \\
\hline & 3.4 & $0.9-1.0$ & 4.4 & \\
\hline
\end{tabular}




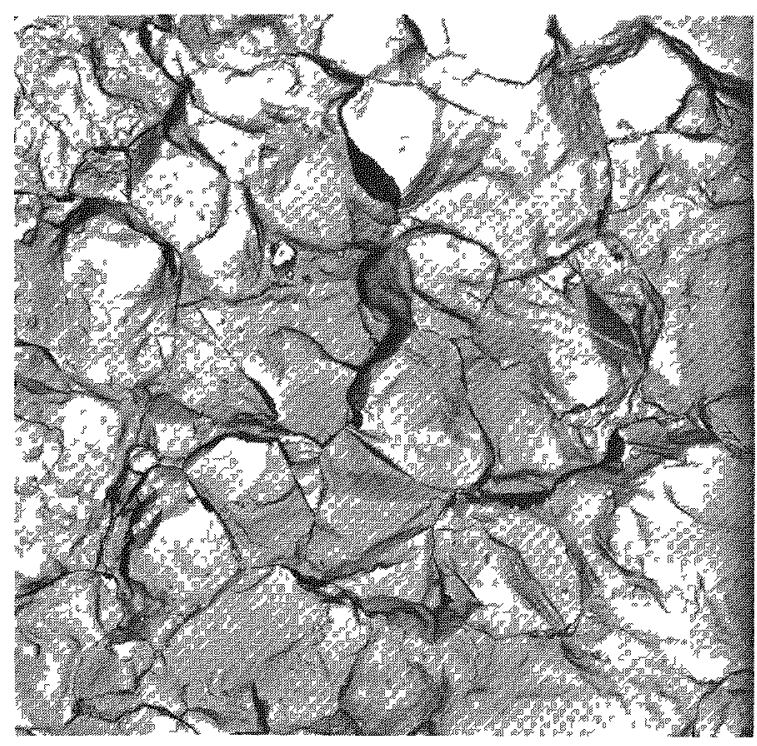

(a)

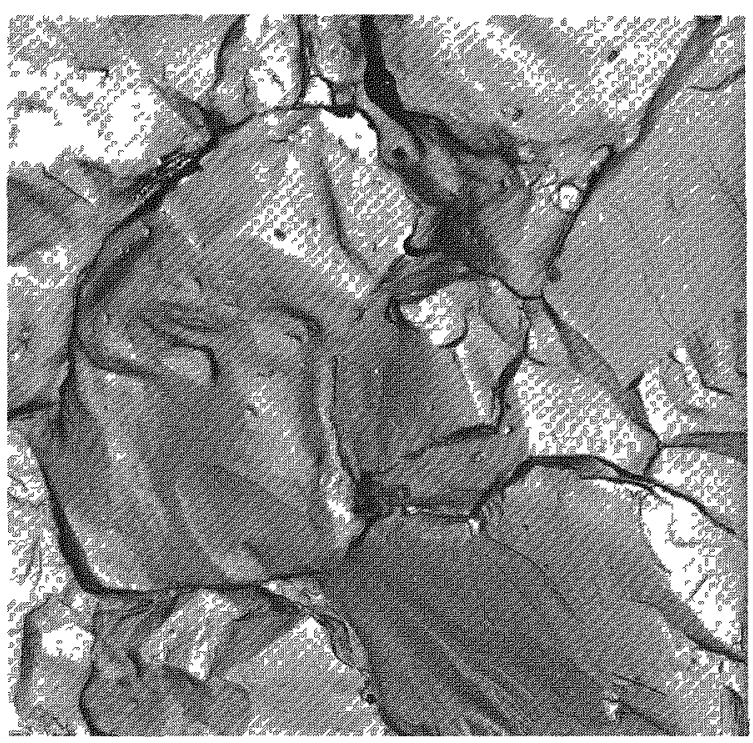

(b)

Fig. 5. Microstructure from Unrestructured Region of Steady-state Element PNL-17-10. The fractional radius $\mathrm{r} / \mathrm{r}_{\mathrm{O}} \approx 0.80$, and the EBR-II irradiation temperature $\approx 1000^{\circ} \mathrm{C}$. (a) Mag. $1128 \mathrm{X}$. Neg. No. MSD-171103. (b) Mag. 3666X. Neg. No. MSD-171116.

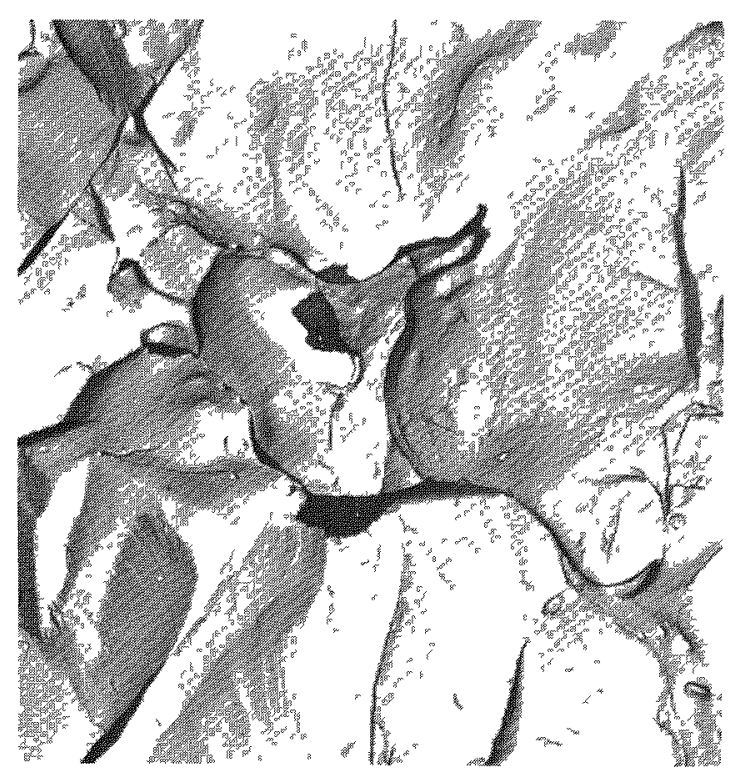

Fig. 6. Microstructure from Equiaxed Region of Steady-state Element PNL-17-10. The fractional radius $r / r_{O}=0.62$, and the EBR-II irradiation temperature $\approx 1300^{\circ} \mathrm{C}$. Mag. 1974X. Neg. No. MSD-171095.
0.73-0.41 r/ ro, the fractures become progressively more intergranular. A comparison of Fig. 6 at $0.62 \mathrm{r} / \mathrm{r}_{\mathrm{o}}$ with Fig. $7 a$ at $0.42 \mathrm{r} / \mathrm{r}_{0}$ indicates the increasingly intergranular nature of the fractures as the center of the fuel is approached. These figures also indicate the increasing size of the bubbles (or pores containing fission gas) that are found on grain boundaries. These grainboundary bubbles increase in size from $\sim 0.5 \mu \mathrm{m}$ near the "cool" edge of the restructured equiaxed region to $\sim 5.0 \mu \mathrm{m}$ near the "hot" edge of the region. Among the bubbles observed on grain boundaries, evidence exists, from the noncircular bubble cross sections seen in Fig. 7a, that substantial bubble coalescence has occurred. Bubbles observed on cleavage surfaces (intragranular fracture surfaces), Fig. $7 \mathrm{~b}$, a re still randomly dis tributed and $\sim 650 \AA$ in diameter. The columnar region from $\sim 0.41 \mathrm{r} / \mathrm{r}_{\mathrm{O}}$ to the fuel center, as represented by Fig. $8 \mathrm{a}$, shows extensive bubble coalescence on grain boundaries with the bubbles often elongated in the direction of the longitudinal axis of the grains. The grainboundary bubbles are interlinked, as the center of the fuel is reached, to provide a fission-gas path. The degree of linkage is a function of burnup and power as shown previously. ${ }^{11,12}$ 


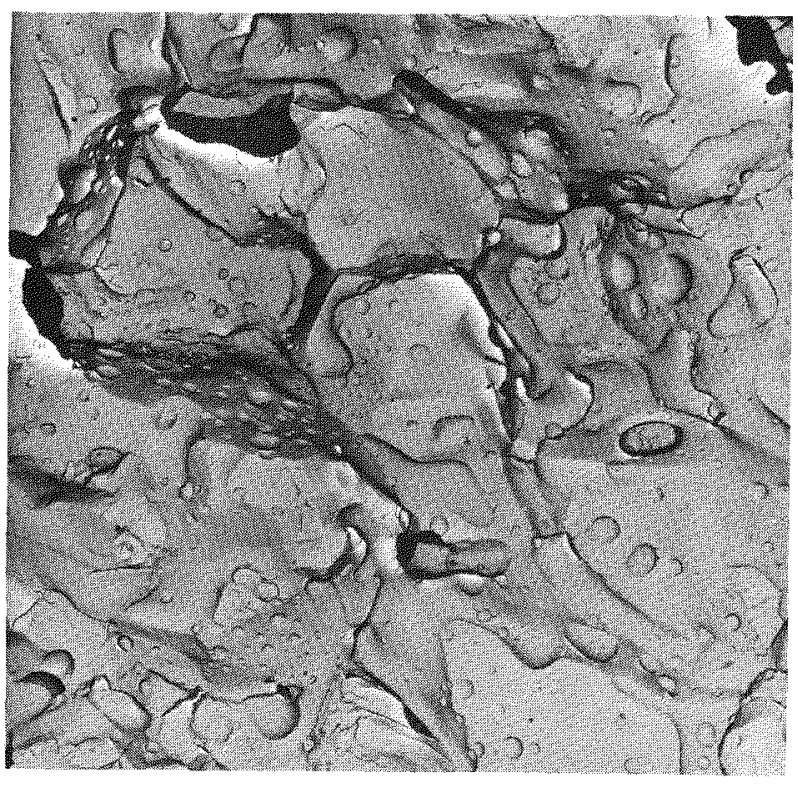

(a)

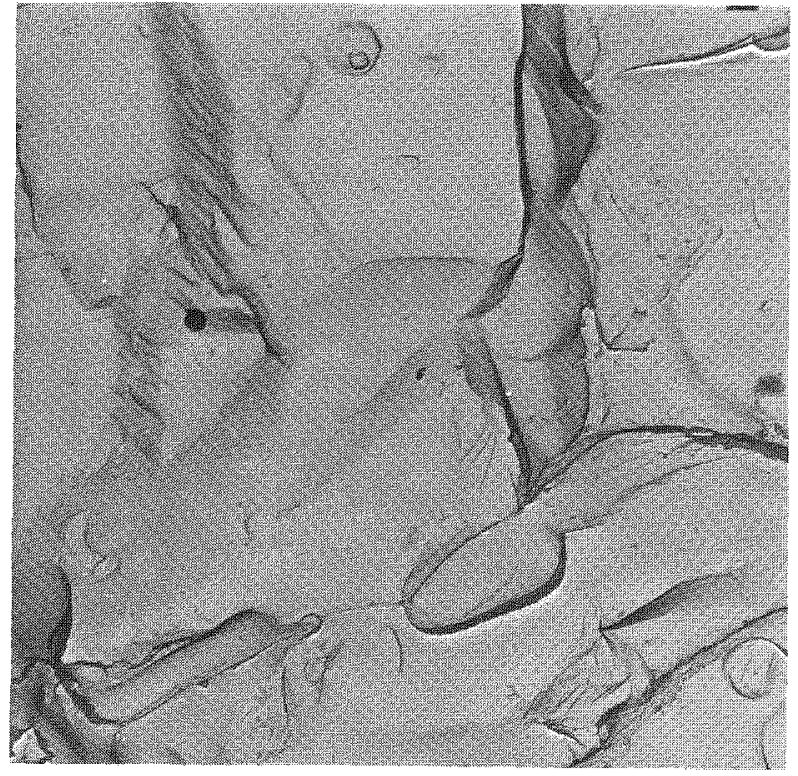

(b)

Fig. 7. Microstructure at Equiaxed-columnar-region Boundary of Steady-state Element PNL-17-10. The fractional radius $\mathrm{r} / \mathrm{r}_{\mathrm{O}} \approx 0.43$, and the EBR-II irradiation temperature $\approx 1550^{\circ} \mathrm{C}$. (a) Mag. $1200 \mathrm{X}$. Neg. No. MSD-171106. (b) Mag. 3900X. Neg. No. MSD-170949.

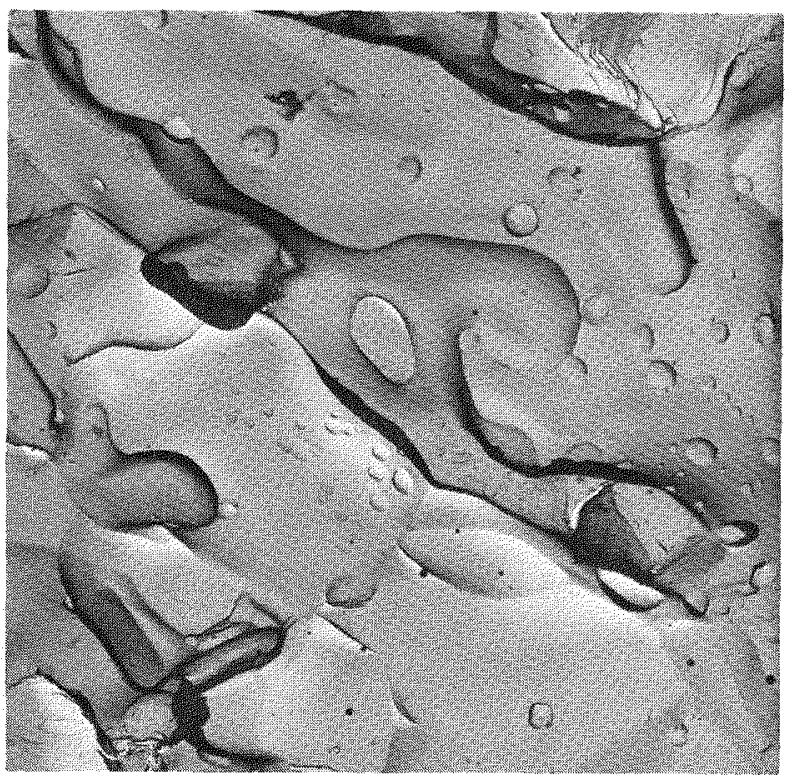

(a)

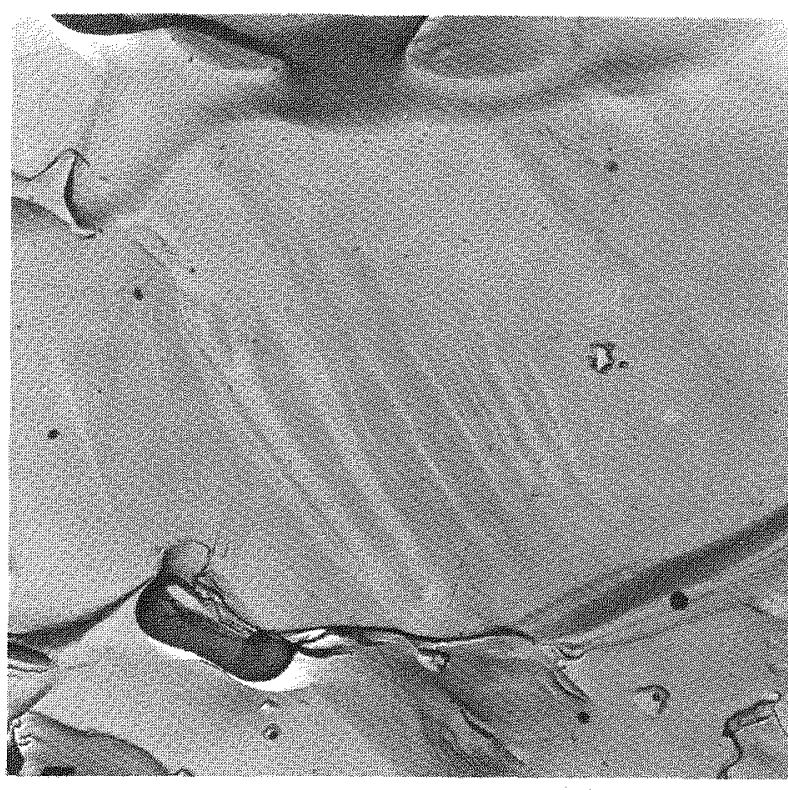

(b)

Fig. 8. Microstructure from Columnar Region of Steady-state Element PNL-17-10. The fractional radius $x / r_{0} \approx 0.27$, and the EBR-II irradiation temperature $\approx 1700^{\circ} \mathrm{C}$. (a) Mag. 2100X. Neg. No. MSD-171108. (b) Mag. 3900X. Neg. No. MSD-171086. 
Figure $8 b$ shows that the $\sim 650$ - $\AA$ intragranular bubbles are randomly distributed on cleavage surfaces, as has been observed in other regions of the fuel. Bubble size is apparently independent of radial position at $\sim 650-\AA$ diameter; however, unresolved smaller intragranular bubbles may be present, since $\sim 500 \AA$ is the limit of resolution for this replication technique. On the other hand, the grain-boundary bubble size and distribution are dependent on radial position (or temperature of the fuel). The nearer the fuel center, the larger and more numerous are the intergranular bubbles.

The character of the cross section from the transient-tested element (PNL-17-24) is similar in many ways. The "unrestructured" region of the fuel, 1.00-0.73 r/ $\mathrm{r}_{0}$, fractured in an intragranula mode with some intergranular fractures. A few pores at grain boundaries are in evidence (Fig. 9a). However, in this region a relatively high density of $\sim 650-\AA$ bubbles is found on cleavage surfaces (Fig. 9b). Compare Figs. $9 \mathrm{a}$ and $9 \mathrm{~b}$ with Figs. $5 \mathrm{a}$ and $5 \mathrm{~b}$ for a similar radial location from PNL-17-10. In Fig. 9b, bubbles of from 1000 - to $2000-\AA$ diameter appear on grain boundaries, but were not observed in the corresponding region of PNL-17-10. These additional grain-boundary bubbles must have precipitated or coalesced during the transient from regions in or immediately adjacent to the boundary, since long-range, short-time migration at this temperature $\left(<2000^{\circ} \mathrm{C}\right)$ is not likely.

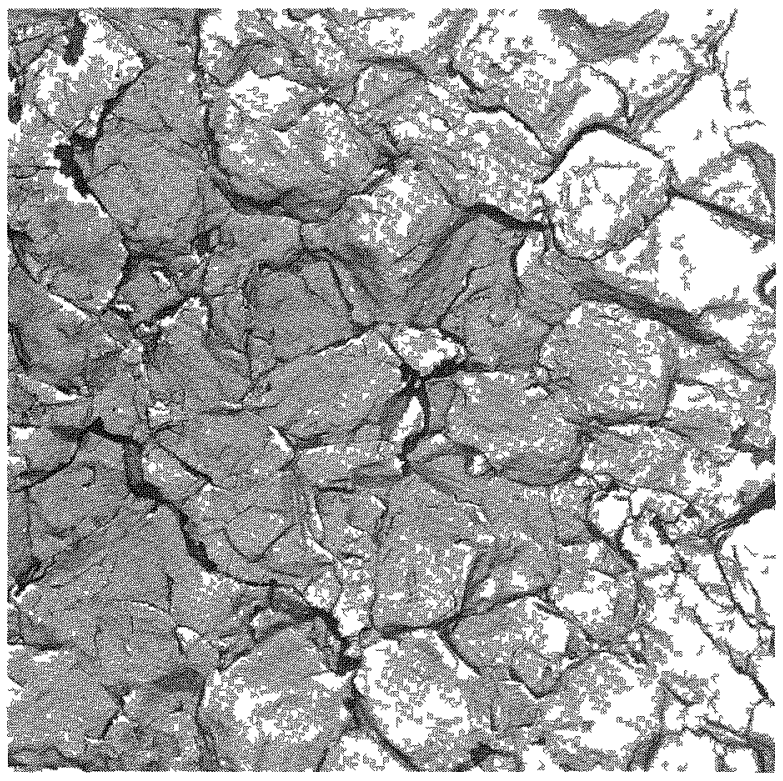

(a)

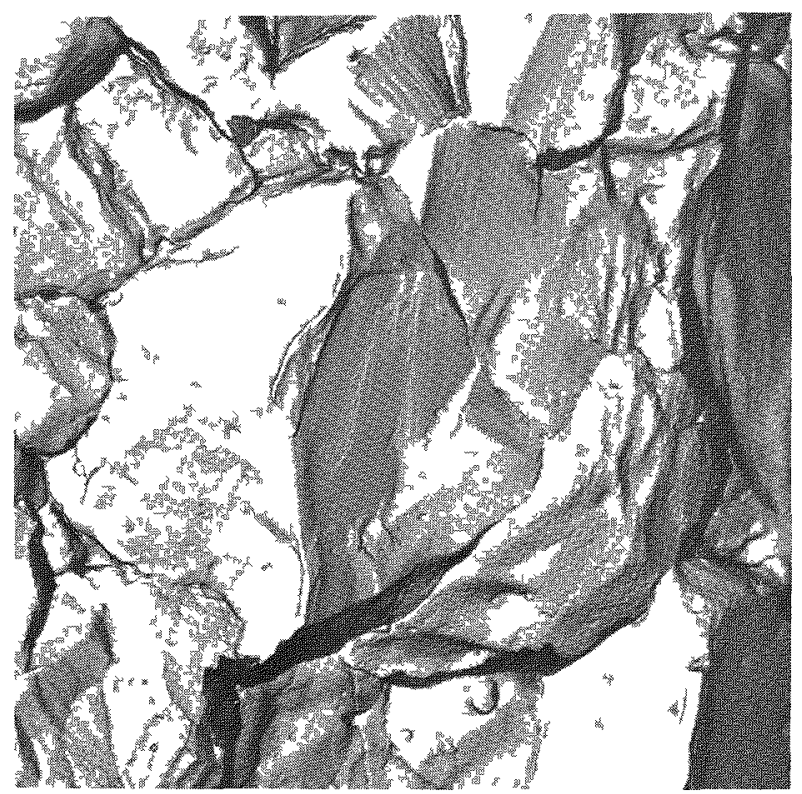

(b)

Fig. 9. Microstructure from Unrestructured Region of Transient-test Element PNL-17-24. The fractiona1 radius $\mathrm{r} / \mathrm{r}_{\mathrm{O}} \approx 0.83$, and the maximum transient temperature $\approx 1950^{\circ} \mathrm{C}$ (a) Mag. $1200 \mathrm{X}$. Neg. No. MSD-171045. (b) Mag. 3900X Neg. No. MSD-171069

For the equiaxed region, the fractures were predominantly intergranular with some intragranular fractures. On the grain boundaries, bubbles of 
two distinct sizes were observed (Fig. 10). One bubble group is similar in size and distribution to that observed in the corresponding region of the nontransient-tested specimen, that is, ranging in size from $\sim 0.5$ to $\sim 5.0 \mu \mathrm{m}$. The other bubbles are smaller in size $(<0.5 \mu \mathrm{m})$ and more uniformly distributed. Again, as in the sibling element, the bubbles in both size ranges were larger the nearer the center of the fuel, that is, the higher the temperature in EBR-II and TREAT. Intragranular bubbles were randomly distributed and $\sim 650 \AA$ in diameter, but with a higher density than in the sibling element. This randomness of intragranular bubbles also holds for the columnar region. However, the density was about the same as shown in Fig. 11.

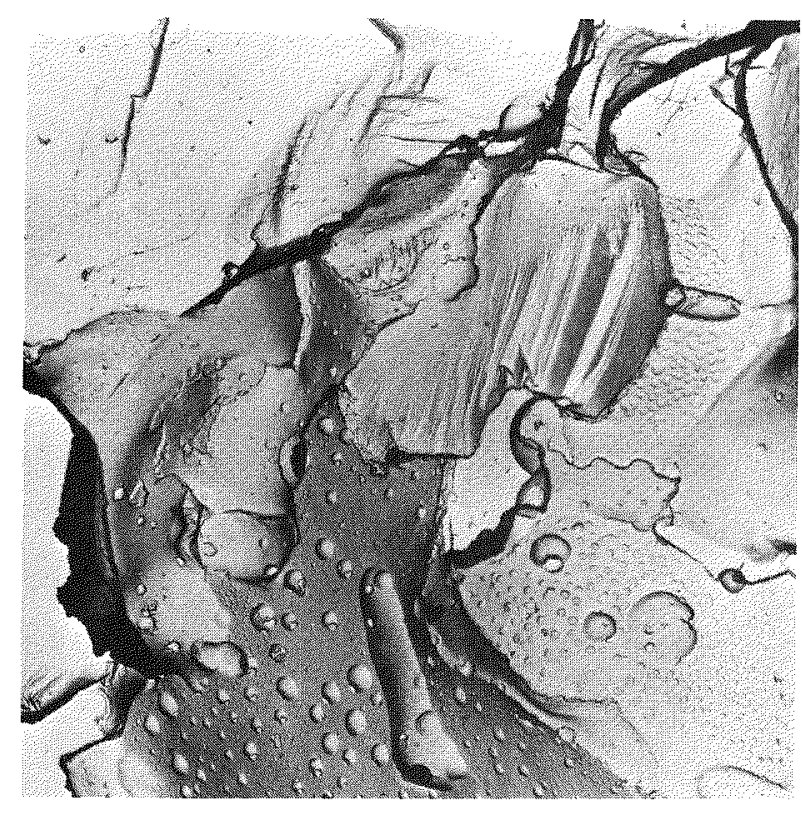

Fig. 10

Microstructure from Equiaxed Region of Transient-test Element PNL-17-24. The fractional radius $r / r_{O}=0.64$, and the maximum transient temperature $\approx 2400^{\circ} \mathrm{C}$. Mag. 2100X. Neg. No. MSD-171126.

Fig. 11

Intragranular Surface from Columnar Region of Transient-test Element PNL-17-24. The fractional radius $\mathrm{r} / \mathrm{r}_{\mathrm{O}}=0.35$, and the maximum transient temperature $\approx 2700^{\circ} \mathrm{C}$. Mag. $3900 \mathrm{X}$. Neg. No. MSD-171014.

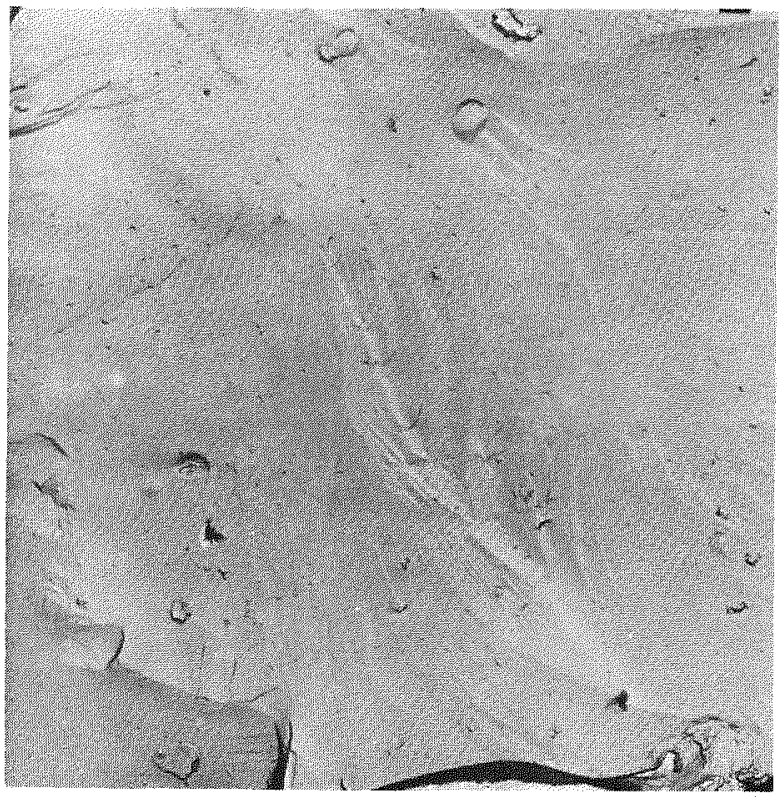


The grain-boundary bubbles in the columnar region (Fig. 12) were of two distinct sizes, as in the equiaxed region, but considerable evidence of small bubble coalescence existed. For grain-boundary bubbles near the center of the fuel, this became quite pronounced, as shown in Fig. $12 \mathrm{~b}$, at $0.17 \mathrm{r} / \mathrm{r}_{\mathrm{o}}$, where the smaller bubbles appear to be moving toward the larger, elongated bubbles outlining the columnar grains. The rate of gas-bubble migration was calculated as $\sim 4 \mu \mathrm{m} / \mathrm{sec}$ by dividing the average distance traveled by the time at a temperature sufficient to cause motion. The rate corresponded with that calculated by surface diffusion. ${ }^{13}$ Both volume and vapor-phase diffusion were found to yield velocities several orders of magnitude lower for these $\sim 0.2-\mu \mathrm{m}$ -
dia bubbles.

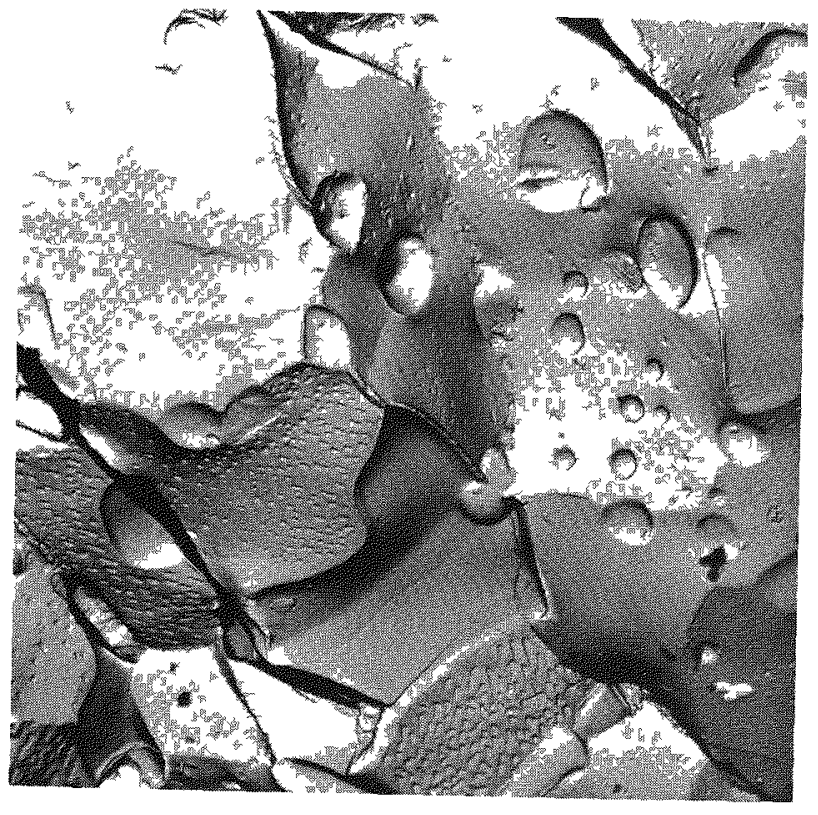

(a)

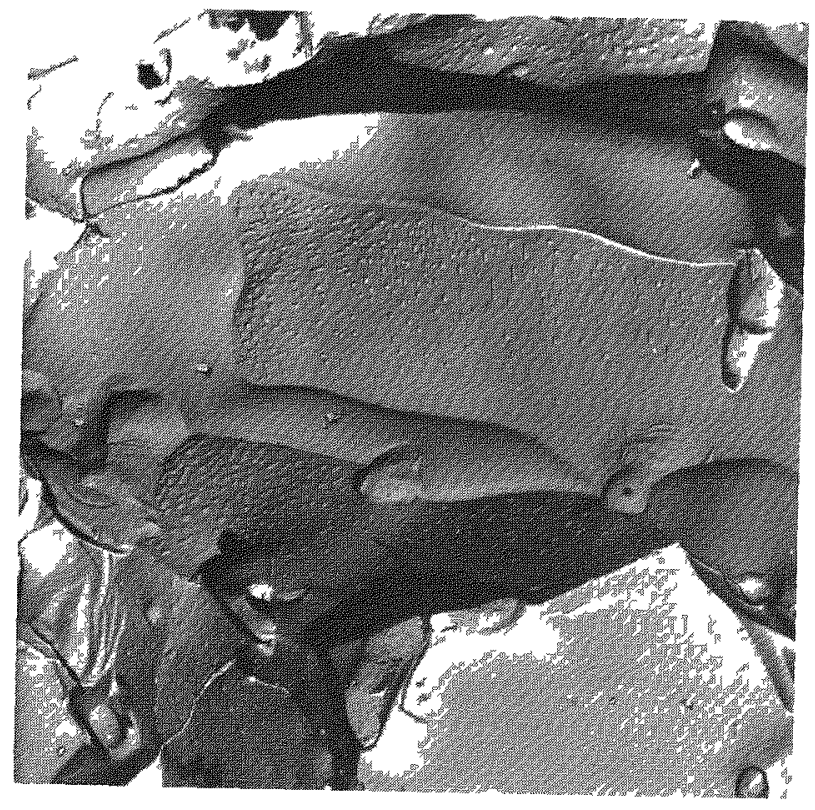

(b)

Fig. 12. Microstructures from Columnar Region of Transient-test Element PNL-17-24. The fractional radius $r / r_{O} \approx 019$, and the maximum transient temperature $\approx 2750^{\circ} \mathrm{C}$. (a) Mag. 2100X. Neg No. MSD-171033. (b) Mag. 2100X Neg. No. MSD-171034. 


\section{QUANTITATIVE TEM RESULTS}

Quantitative measurements of the intergranular and intragranular fission-gas bubble sizes and shapes were made on corresponding midplane radial cross sections of elements PNL-17-10 and -24 . Calculated values of the amount of fission gas trapped at the grain boundaries for several radial positions were made from measurements of bubble sizes and shapes obtained from replica electron micrographs of fractured fuel surfaces. Two tracings of each intergranular fracture were made. One outlined all the intergranular bubbles with circular cross sections, i.e., spherical-shape bubbles; the other tracing showed all bubbles with noncircular cross sections, for example, interconnected spherical bubbles or long, cylindrical-shaped bubbles that have resulted from the many coalesced bubbles. These tracings were analyzed using a Quantimet 720 image analyzer.

The size distribution of spherical bubbles at grain boundaries in the columnar zone (at $r / r_{0}=0.40$ and 0.30 ) was found to be different for the two rods, as shown in Figs. 13 and 14. PNL-17-24 has the form of a hyperbola. with decreasing bubble number with increasing bubble size. PNL-17-10 has the standard distribution form with a peak at $\sim 0.4 \mu \mathrm{m}$. Crossover of the two curves occurs at $\sim 0.6 \mu \mathrm{m}$, above which the curves generally approach one another. This indicates that, although small bubbles nucleated and coalesced during the transient, little, if any, coalescence or growth of large spherical bubbles occurred.

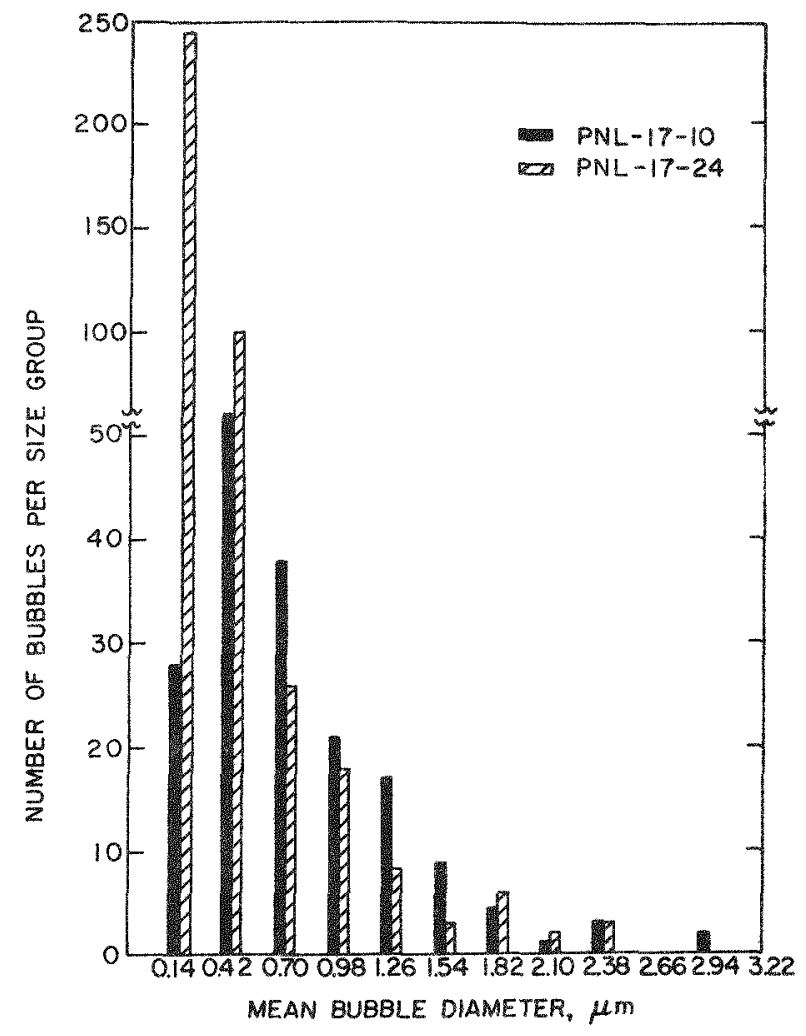

Fig. 13. Grain-boundary Bubble-size Distribution at $\mathrm{r} / \mathrm{r}_{\mathrm{o}}=0.40$. Neg. No. MSD-59636.

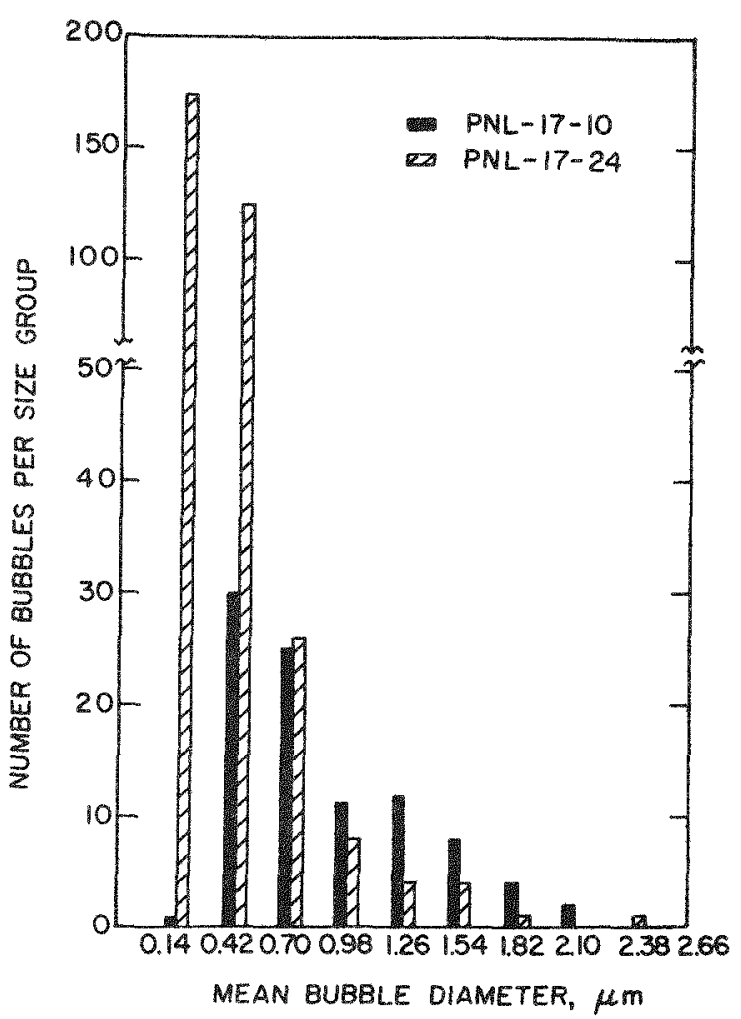

Fig. 14. Grain-boundary Bubble-size Distribution at $r / r_{0}=0.30$. Neg. No. MSD -59637 . 
Spatial distributions were obtained for intragranular bubbles for both rods as a function of radius of the fuel (Fig. 15). As noted in Sec. III, in all

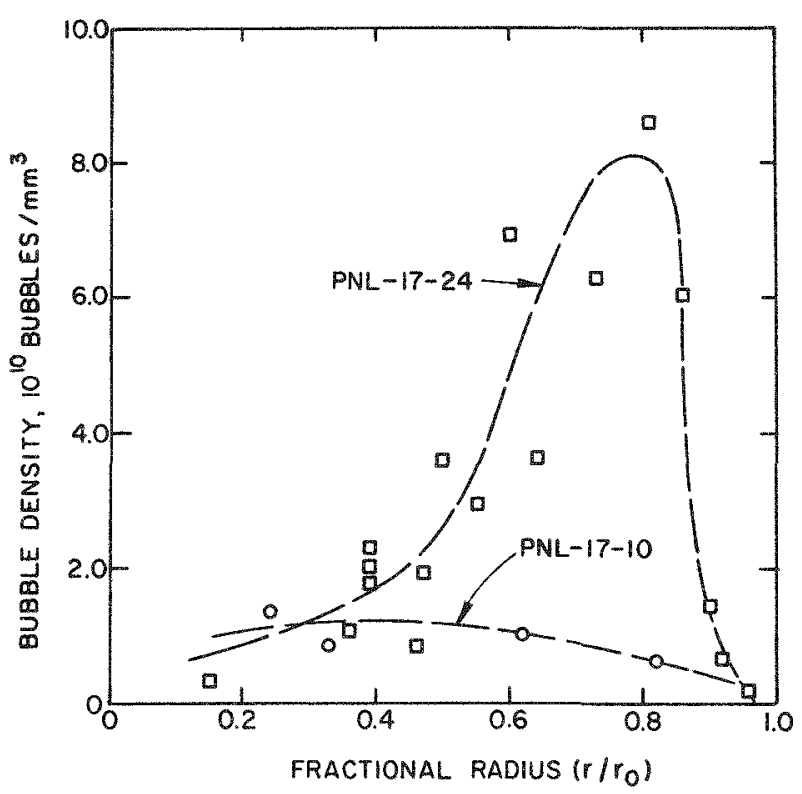

Fig. 15. Intragranular Bubble Density as a Function of Fractional Radius. Neg. No. MSD-59635. but a few cases, the intragranular bubbles were $650 \AA$ in diameter. In addition, the fractures toward the center became increasingly more intergranular. Therefore, toward the center, fewer intragranular surfaces were available for measurement. Qualitatively, the results are similar to those given above for grain-boundary bubbles in the columnar region. The PNL-17-24 bubble number density increased gradually from the center toward the unrestructured region then decreased toward the edge, whereas the PNL-17-10 bubble density had a fairly constant value. Crossover occurred at $\sim 0.3 \mathrm{r} / \mathrm{r}_{\mathrm{O}}$, which lies in the columnar region. Thus, the transient-tested rod (PNL-17-24) contains a greate $x$ number of intragranular bubbles, generally decreasing toward the center as a result of either migration to the grain boundaries or the presence of fewer bubble nuclei in the columnar region.

A quantitative determination was made of the total fission-gas content per unit volume of fuel for each rod in the columnar region where grainboundary bubbles were well defined. This is obtained by multiplying the total fission-gas content per unit area of grain boundary by the surface-to-volume ratio term. Sv, which is equal to twice the length of the linear intercepts determined from the photomicrograph. In the analysis, several simplifying assumptions were made: (a) Harrison's ${ }^{14}$ modified gas law holds; (b) equilibrium between pressure, $P$, and surface tension, $\gamma$, exists; $i . e ., P=2 \gamma / r$ for spherical bubbles, and $P=\gamma / r$ for cylindrical bubbles, where $r$ is the bubble radius; (c) nonspherical bubbles were assumed to be right-circular cylinders; (d) $y \approx 600 \mathrm{ergs} / \mathrm{cm}^{2} ;{ }^{13}$ and $(\mathrm{e})$ the correction for inclined planes was neglected. (The calculated and measured total areas were found to be in agreement.)

Using these assumptions and a value of $T$ from Fig. 1 , the fission-gas atom density contributed by the grain boundaries was found to be about the same for PNL-17-10 and -24 at $\sim 1.8 \times 10^{18}$ atoms $/ \mathrm{cm}^{3}$ (Table II). The contribution from the matrix was determined for PNL-17-24 only, since insufficient replicas were available for PNL-17-10 that showed intragranular fractures in this region. The number of fission-gas bubbles $\sim 650 \AA$ in diameter in the columnar region was found to be $\sim 1.5 \times 10^{13} / \mathrm{cm}^{3}$ of fuel, as seen from Table III and Fig. 15. From Harrison's equation of state for $\sim 650-\AA$ bubble size, 
$\sim 3.0 \times 10^{5}$ atoms/bubble yield $4.5 \times 10^{18}$ atoms $/ \mathrm{cm}^{3}$ and a total of $6.3 \times$ $10^{18}$ atoms $/ \mathrm{cm}^{3}$, which compares favorably with the value of $8.3 \times 10^{18}$ atoms/ $\mathrm{cm}^{3}$ found by laser sampling, as discussed in Sec. $\mathrm{V}$ below.

TABLE II. Grain-boundary Fission-gas Atom Densities

\begin{tabular}{|c|c|c|c|c|c|}
\hline \multirow[b]{2}{*}{ Element } & \multirow{2}{*}{$\begin{array}{l}\text { Radial } \\
\text { Position } \\
r / r_{0}\end{array}$} & \multirow{2}{*}{$\begin{array}{c}\text { Estimated } \\
\text { Temperature, } \\
{ }^{\circ} \mathrm{K}\end{array}$} & \multirow{2}{*}{$\begin{array}{c}\text { Surface/Volume } \\
\mathrm{Sv} \\
\mathrm{mm}^{-1}\end{array}$} & \multicolumn{2}{|c|}{ Fission-gas Densities } \\
\hline & & & & $\begin{array}{l}\text { Grain Boundary, } \\
\text { atoms } / \mathrm{mm}^{2}\end{array}$ & $\begin{array}{l}\text { Fuel, } \\
\text { atoms } / \mathrm{mm}^{3}\end{array}$ \\
\hline PNL-17-10 & $\begin{array}{l}0.3 \\
0.4\end{array}$ & $\begin{array}{l}1943 \\
1853\end{array}$ & $\begin{array}{l}132.0 \\
118.7\end{array}$ & $\begin{array}{l}2.03 \times 10^{13} \\
1.68 \times 10^{13}\end{array}$ & $\begin{array}{l}2.69 \times 10^{15} \\
1.99 \times 10^{15}\end{array}$ \\
\hline PNL-17-24 & $\begin{array}{l}0.3 \\
0.4 \\
0.4\end{array}$ & $\begin{array}{l}2870 \\
2815 \\
2815\end{array}$ & $\begin{array}{l}112.8 \\
103.2 \\
103.2\end{array}$ & $\begin{array}{l}1.34 \times 10^{13} \\
1.67 \times 10^{13} \\
1.40 \times 10^{13}\end{array}$ & $\begin{array}{l}1.51 \times 10^{15} \\
1.72 \times 10^{15} \\
1.44 \times 10^{15}\end{array}$ \\
\hline
\end{tabular}

TABLE III. Intragranular Bubble Densities

\begin{tabular}{|c|c|c|c|}
\hline Element & $\begin{array}{l}\text { Radial } \\
\text { Position } \\
r / r_{0}\end{array}$ & $\begin{array}{c}\text { Bubbles } / \mathrm{mm}^{2} \\
\mathrm{~N}_{\mathrm{a}}^{\mathrm{a}}\end{array}$ & $\begin{array}{c}\text { Bubbles } / \mathrm{mm}^{3} \\
\mathrm{~N}_{\mathrm{v}}{ }^{3}\end{array}$ \\
\hline PNL-17-10 & $\begin{array}{l}0.24 \\
0.33 \\
0.62 \\
0.82\end{array}$ & $\begin{array}{l}5.78 \times 10^{5} \\
3.54 \times 10^{5} \\
4.41 \times 10^{5} \\
2.68 \times 10^{5}\end{array}$ & $\begin{array}{l}1.33 \times 10^{10} \\
0.82 \times 10^{10} \\
1.02 \times 10^{10} \\
0.62 \times 10^{10}\end{array}$ \\
\hline PNL-17-24 & $\begin{array}{l}0.15 \\
0.36 \\
0.38 \\
0.46 \\
0.47 \\
0.50 \\
0.55 \\
0.60 \\
0.64 \\
0.73 \\
0.81 \\
0.86 \\
0.90 \\
0.92 \\
0.96\end{array}$ & $\begin{array}{l}1.56 \times 10^{5} \\
4.69 \times 10^{5} \\
3.97 \times 10^{5} \\
3.70 \times 10^{5} \\
8.35 \times 10^{5} \\
15.5 \times 10^{5} \\
12.8 \times 10^{5} \\
30.0 \times 10^{5} \\
15.7 \times 10^{5} \\
27.2 \times 10^{5} \\
37.1 \times 10^{5} \\
26.2 \times 10^{5} \\
6.20 \times 10^{5} \\
2.86 \times 10^{5} \\
0.81 \times 10^{5}\end{array}$ & $\begin{array}{l}0.36 \times 10^{10} \\
1.08 \times 10^{10} \\
2.07 \times 10^{10} \\
0.85 \times 10^{10} \\
1.93 \times 10^{10} \\
3.58 \times 10^{10} \\
2.95 \times 10^{10} \\
6.93 \times 10^{10} \\
3.63 \times 10^{10} \\
6.29 \times 10^{10} \\
8.57 \times 10^{10} \\
6.05 \times 10^{10} \\
1.43 \times 10^{10} \\
0.66 \times 10^{10} \\
0.19 \times 10^{10}\end{array}$ \\
\hline
\end{tabular}

Laser sampling of retained fission gas was performed by the Chemical Engineering Division on midplane sections from PNL-17-10 and -24 . In this procedure, a focused laser beam vaporizes a small quantity of fuel, which releases the retained gases to a collection system. The ${ }^{85} \mathrm{Kr}$ collected is 
counted (the other fission-gas species are nonradioactive) and related to the volume of the cavity formed, which is determined by measurement from a

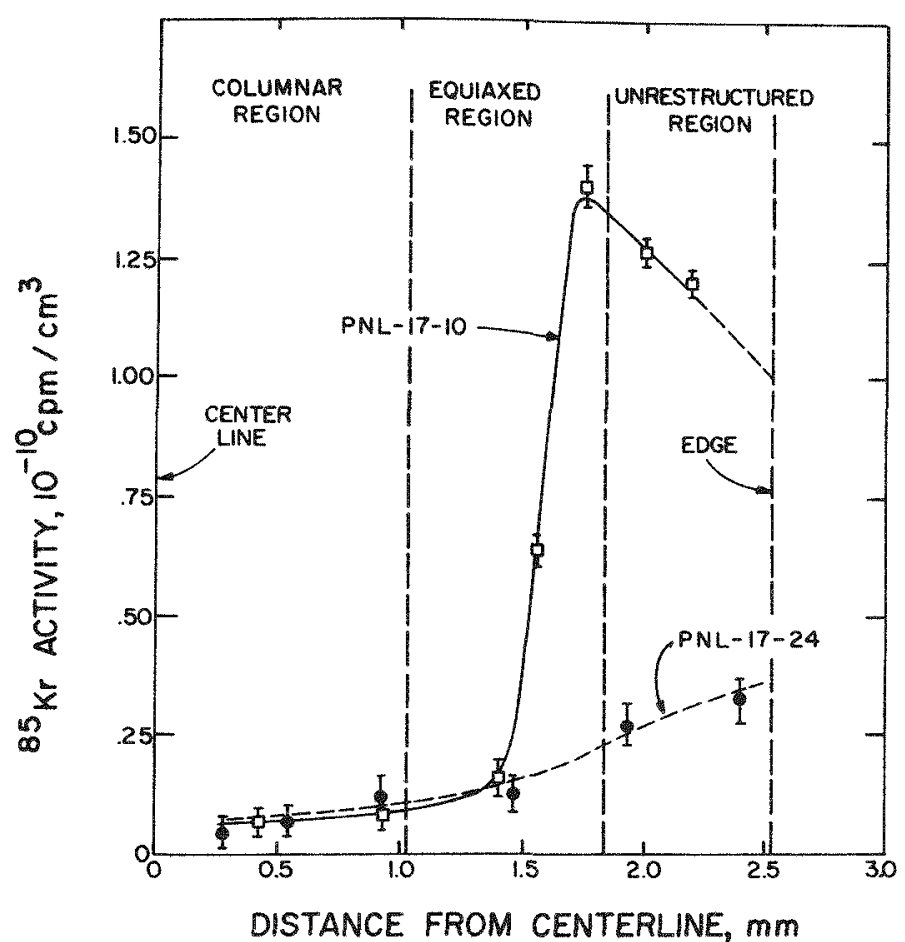

Fig. 16. Comparison of Laser-sampling Data for PNL-17-24 and Sibling PNL-17-10. Neg. No. MSD-58765. negative replica. The results are shown in Fig. 16.

The amount of retained gas in PNL-17-10 is low in the columnax region, increases greatly in the equiaxed region, and then decreases slightly in the unrestruc tured region. The drop in retention shown in the unrestructured region of the sibling rod has been found in other rods ${ }^{15}$ and is due to a combination of fine cracks, open porosity, and recoil effects in this region. For PNL-17-24, it it seen from Fig. 16 that krypton has been released from this region as a result of the transient.

An estimate was made of the total fission-gas content in PNL-17-10 by multiplying the computed ${ }^{85} \mathrm{Kr}$ atom density by the ratio $(\mathrm{Kr}+\mathrm{Xe}) /{ }^{85} \mathrm{Kr}$. A value of 140 for this ratio was chosen

for the gas retained in the fuel, after available mixed-oxide data ${ }^{16}$ were reviewed. The average atom densities and retention percentages are shown in Table IV for each fuel-structure region. Multiplying the volume fraction,

TABLE IV. Midplane Gas Contents in PNL-17-10 and -24

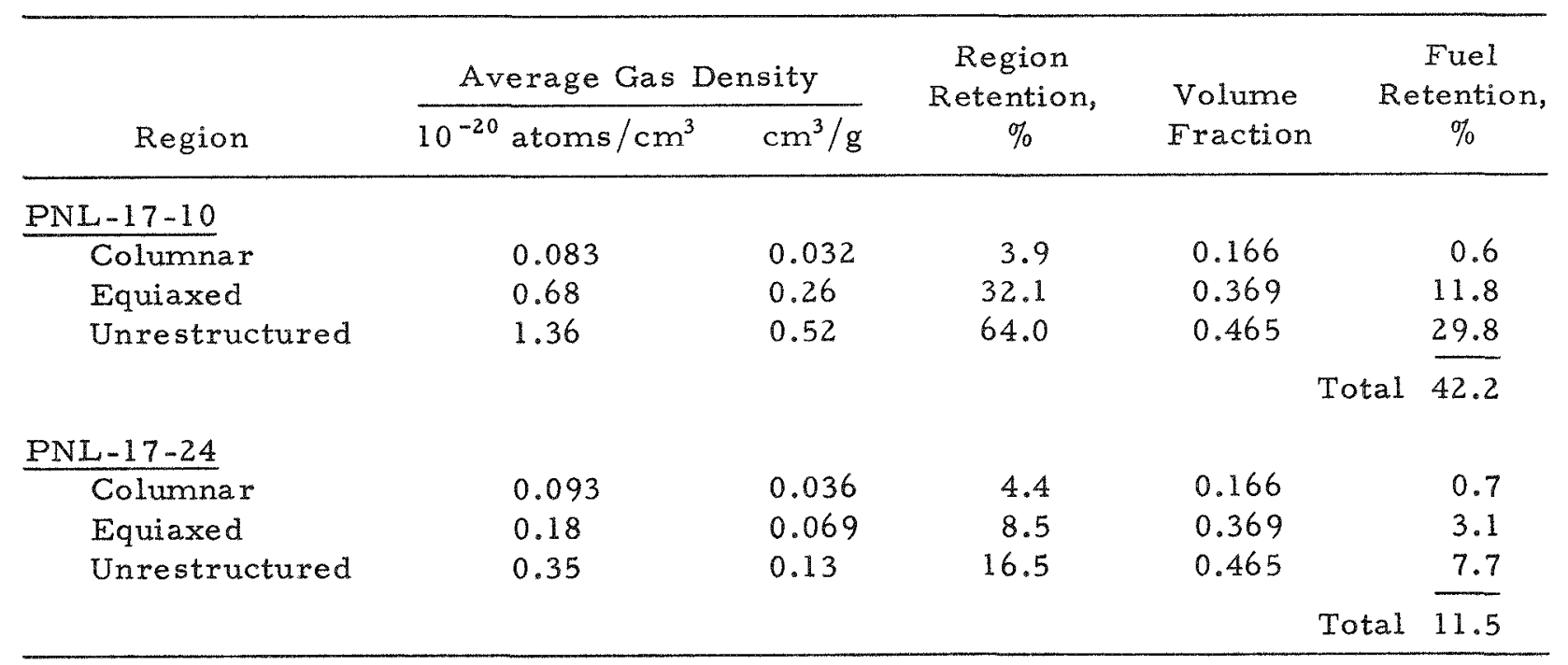


determined metallographically, by the region retention and summing gives the total fuel retention of $42.2 \%$. This yields a midplane release of $57.8 \%$, or an average of $\sim 48 \%$, in good agreement with the measured gas release of $47.5 \%$ for the entire rod.

The average atom densities and retention percentages were also calculated for PNL-17-24, as listed in Table IV. The total fuel retention of $11.5 \%$, and hence a release of $88.5 \%$, indicates that the axial extent of the transient release was limited to areas adjacent to the midplane. However, this result is questionable, since it relies on only three data points in the. combined equiaxed and unrestructured regions, and it is not consistent with the measured gas release of $56.2 \%$ for the entire rod. This will be verified at a later time by additional laser sampling at this and other axial positions.

\section{DISCUSSION}

\section{A. Steady-state Characterization}

It was stated in Sec. I that the distribution and morphology of fission gas during steady state are of primary concern in assessing transient swelling behavior. The laser sampling and TEM results on PNL-17-10 go far in establishing these conditions. In the unrestructured region, $\sim 64 \%$ of the gas produced at the midplane has been retained. Most of this retained gas is either in solution or in small (unresolvable) bubbles within the matrix. The remaindex of the gas is located in the $\sim 650-\AA$ intragranular bubbles and in the grain boundaries. As suggested by Nelson, ${ }^{17}$ it is also likely that a concentration gradient exists near grain boundaries due to re-solution. From the data of Fig. 15 or Table III, the intragranular gas-bubble density in the unrestructured region is $\sim 1 \times 10^{13}$ bubbles $/ \mathrm{cm}^{3}$ or $\sim 3 \times 10^{18}$ atoms $/ \mathrm{cm}^{3}$. This is $\sim 2 \%$ of the total gas in the region $\left(1.36 \times 10^{20}\right.$ atoms $/ \mathrm{cm}^{3}$, as given in Table IV). These values are in fair agreement with those calculated by Ronchi and Matzke: ${ }^{18} 0-8 \%$ in intragranular bubbles, $3-17 \%$ in grain boundaries, and $97-75 \%$ in solution. (The spread in values is due to different values applicd to the diffusion constant at the temperature of the region.) Their calculations are given in Table V.

TABLE V. Calculated Fission-gas Locationsa

\begin{tabular}{cccc}
\hline \multirow{2}{*}{$\begin{array}{c}\text { Temperature, } \\
{ }^{\circ} \mathrm{C}\end{array}$} & \multicolumn{3}{c}{ Fission-gas Location, $\% \mathrm{~b}$} \\
\cline { 2 - 4 } 1000 & $75(97)$ & $17(3)$ & $8(0)$ \\
1200 & $2(71)$ & $47(22)$ & $49(7)$ \\
1500 & $\sim 0(\sim 0)$ & $96(16)$ & $4(84)$ \\
2000 & $\sim 0(\sim 0)$ & $\sim 98(89)$ & $\sim 2(11)$ \\
2500 & $\sim 0(\sim 0)$ & $\sim 99(98)$ & $\sim 1(2)$ \\
\hline
\end{tabular}

apage 49 of Ref. 18. Data are for a 1-year, fast-flux irradiation.

bData in parentheses are for lower assumed gas-diffusion coefficients.

${ }^{C}$ Grain-boundary gas is assumed to have escaped to the plenum. 
Ronchi and Matzke also found, in the mixed-oxide $17-\mathrm{kW} / \mathrm{ft}$ irradiation work performed along with their modeling effort, that the intragranular bubble density was fairly constant over the fuel radius, which is also observed in our. work. However, their size distribution was normal, with a maximum of $\sim 300 \AA$. For a lower $(\sim 8.9-\mathrm{kW} / \mathrm{ft})$-power PNL-1 element, bubble diameter was much larger at 1000-1800 $\AA_{0}^{19}$ These data suggest that bubble size at steady state decreases with an increase in fission rate and that the bubble re-solution rate increases with an increase in fission rate.

The inference that re-solution rate is proportional to fission rate may substantiate part of Nelson's re-solution theory. However, the relatively large bubble size compares more favorably to the maximum bubble size of $650 \AA$ that could be pinned by a dislocation in $\mathrm{UO}_{2}$ as predicted by Barnes and Nelson. ${ }^{20}$ Nichols ${ }^{21}$ has estimated this critical size to be $\sim 500 \AA$ before breakaway. More recently, a study by Poeppel and Dias ${ }^{22}$ has shown that a large

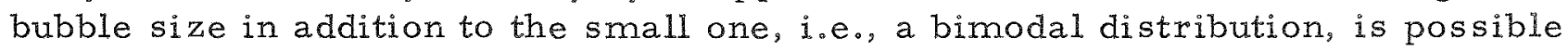
if the re-solution parameter decreases with an increase in bubble size. This would extend the applicability of re-solution theory.

Under steady-state conditions, the equiaxed region operates at temperatures of $\sim 1100-1550^{\circ} \mathrm{C}$, increasing toward the center of the fuel. As seen by superimposing Fig. 1 on Fig. 16, the gas concentration drops rapidly above 1200-1300 $\mathrm{C}$. Above this temperature range, migration and coalescence of bubbles become appreciable. When the gas reaches the grain boundary, it may escape to the plenum through cracks or equiaxed and columnar grainboundary openings. The gas in solution decreases greatly as well. However, intragranular bubbles still contain 4-5\% of the gas produced in this region, as mentioned in this section and shown in Fig. 15. This agrees with the calculated results of Ronchi and Matzke given in Table V, which show a great change in gas concentration between 1200 and $1500^{\circ} \mathrm{C}$. The gas content of the columnargrain region is similar to that obtained for the hot portion of the equiaxedgrain region. Figure 16 shows a gradual decrease in gas content toward the small central void. This is probably due to a decrease in the number of intragranular bubbles.

As stated in Sec. V, the laser-sampling technique has characterized fairly well the location of all fission gas retained in the fuel under steadystate reactor operation. The columnar-grain region and the hot portion of the equiaxed-grain region contain little gas, whereas the cooler portion of the equiaxed and the entire unrestructured grain regions contain most of the gas. Therefore, these regions are most important in evaluating the transient behavior.

\section{B. Post-TREAT Characterization}

The post-TREAT distribution and morphology cannot be described as fully as the steady-state case because of the limited number and capability of laser sampling and TEM. However, several differences have been observed that can be attributed to the transient. 
In the unrestructured region, the gas content has dropped considerably from the steady-state case. The gas retention at the midplane is estimated to be $\sim 17 \%$, which, as noted in Sec. V, is probably too low. However, this region is the largest reservoir of fission gas, part of which could be released as a result of thermal-shock-induced intragranular cracking. The TEM results have shown that little fission gas has precipitated at or migrated to the grain boundaries. The density of intragranular bubbles, however, has increased by about an order of magnitude because of the transient, as shown in Fig. 15.

The source of the increased number of $\sim 650-\AA$-dia intragranular bubbles in the unrestructured region must be either from bubbles too small to be resolved by the replica $(<500 \AA)$ or from solid solution. From the calculations of Ronchi and Matzke (Table V), ${ }^{18}$ it was determined that most of the gas in the region is in solution. If small bubbles are present, re-solution theory predicts that they will probably be smaller than $100 \AA$, even if the bimodal dis tribution proposed by Poeppel and Dias is accepted. In addition, the small bubble density is low in the unrestructured region, as seen from Table IV, and thus should not greatly influence the rate at which gas in solution coalesces.

Gruber ${ }^{23}$ has recently used a coalescence model with the DEFORM-SAS codes. His model starts with single fission-gas atoms under the temperature and gradient conditions of a mild over-power transient. The atoms are allowed to coalesce and to migrate at a speed that decreases with an increase in size. For bubbles in the unrestructured region near the equiaxed-zone boundary $\left(r / r_{0}=0.73\right)$ at a transient temperature of $2073^{\circ} \mathrm{C}$, he finds an average limiting bubble size of $664 \AA$. This is in excellent agreement with our observations. This also explains the peak in the intragranular bubble-density-radius plot (Fig. 15) at $r / r_{0} \approx 0.8$. At lower temperatures, bubble coalescence is greatly reduced. At higher temperatures, bubbles are drawn to the grain boundaries where additional coalescences can occur, as seen in Fig. $9 \mathrm{~b}$ and described in Sec. III. Similar observations of increased intragranular-bubble density as a result of a transient have been reported by Culley et al. ${ }^{24}$ The ave rage bubble was $\sim 0.1 \mu \mathrm{m}$ in diameter.

On the basis of the above proposals, it would seem reasonable to as sume that, during steady-state operation, intragranular bubbles can grow to a maximum of $\sim 650 \AA$ in quasi-equilibrium with re-solution rate. These bubbles are most likely pinned to dislocations. Larger bubbles will break away and migrate to grain boundaries. During the transient, the fission gas in small bubbles (if they are present) or in solution can migrate and grow by diffusion and coales cence to form bubbles (up to $\sim 650 \AA$ ) that can be pinned by dislocations. Larger $(>650 \AA)$ bubbles will break away from the dislocations and migrate toward. the grain boundaries.

In the equiaxed region, the amount of gas in solution or in small bubbles is decreasing rapidly toward the hotter portions of the fuel. Thus, during the transient, most of the gas that coalesces can migrate fairly rapidly to the grain 
boundaries, where bubbles $<0.5 \mu \mathrm{m}$ were found somewhat uniformly distributed (Fig. 10). This rapid migration is also evident in the rapid drop of intragranula $x$-bubble density for this region shown in Fig. 15 . In the columnar region, the gas is limited to both the grain boundaries and the intragranular bubbles. During the transient, these bubbles will migrate, probably by surface diffusion, to the grain boundaries or within grain boundaries to the larger, elongated bubbles (Fig. 12b).

C. Transient-induced Fuel Swelling

The intragranula $x$ bubbles created during the transient will cause fuel swelling $(\Delta V / V)$, which may, in turn, lead to cladding strain. The maximum amount of swelling is given by the increment in bubble density $\left(\rho_{\mathrm{S}}\right)$ multiplied by the volume of the bubble $\left(V_{s}\right)$. If the density before the transient is neglected, then

$$
\frac{\Delta V}{V}(r)=V_{S} \rho_{S}(r)
$$

where $(\Delta V / V)(r)$ and $\rho_{S}(r)$ represent the swelling and bubble density as a function of radius (Fig.15). The cladding strain due to the fuel swelling may be evaluated by converting fuel swelling to radial displacement (U). If swelling is isotropic, then

$$
U=\int_{R_{C}}^{R_{0}} \frac{2}{3}\left[\frac{\Delta V}{V}(r)\right] \frac{r d r}{R_{0}}=\frac{2 V_{S}}{3 R_{o}} \int_{R_{C}}^{R_{0}}\left[\rho_{S}(r)\right] r d r
$$

where

$$
\begin{aligned}
& R_{0}=\text { outside fuel radius, } 0.251 \mathrm{~cm}(99 \mathrm{mils}) \\
& \mathrm{R}_{\mathrm{C}}=\text { central-void radius, } 0.0013 \mathrm{~cm}(0.5 \mathrm{mil}),
\end{aligned}
$$

and

$$
r=\text { intermediate radius. }
$$

Several simplications to Eq. 2 may be made. First, the areal limits of the integration may be reduced, since the swelling is essentially confined to the unrestructured region. Second, $\rho_{S}(r)$ may be replaced by a constant $\bar{\rho}_{S}$ $\left(=\pi / 4 \rho_{\max }\right)$ that represents a density value that would yield equal areas below the curve from $R_{e}$ to $R_{0}$, where $R_{e}$ is the outer, equiaxed-region radius. Hence,

$$
\left(\frac{\Delta V}{V}\right)_{\left(R_{O}-R_{e}\right)}=V_{s} \bar{\rho}_{S}=\left(1.44 \times 10^{-13}\right)\left(6.9 \times 10^{10}\right)=9.9 \times 10^{-3}
$$


or about $1 \%$ in the unrestructured region, and

$$
U=\frac{2 V_{s}}{3 R_{o}} \bar{\rho}_{s} \int_{R_{e}}^{R_{o}} r d r=\frac{V_{s} \bar{\rho}_{s}}{3 R_{o}}\left(R_{o}^{2}-R_{e}^{2}\right)
$$

Since $R_{e}=0.73 R_{O^{\prime}}$

$$
\mathrm{U}=0.156\left(\mathrm{~V}_{\mathrm{S}} \overline{\mathrm{P}}_{\mathrm{S}}\right) R_{\mathrm{O}}=0.15 \mathrm{mil} \text {, or about } 0.15 \% \text {. }
$$

This maximum change in radius due to fuel swelling is much smaller than that obtained for simple thermal expansion calculated for PNL-1 7-24 by Royl et al.' This possible increase in fuel radius has not been observed experimentally, since both the pretest and posttest fuel-cladding gap sizes were $\sim 0.75$ mil, which is accurate to $\pm 0.25 \mathrm{mil}$. Also, cladding strain, as measured by profilometry, was essentially zero when compared with that measured after the steady-state operation. The experimental accuracy for profilometry is $\pm 0.1 \mathrm{mil}$. The effect of fuel swelling on cladding strain is small or negligible. In addition, Poeppel and Dias ${ }^{22}$ have shown that gas bubbles might be compressed by thermal stress and actually lead to a negative contribution to swelling.

\section{CONCLUSIONS}

1. Laser sampling coupled with TEM has provided the morphology and distribution of fission gas, for both the steady-state sibling element and the transient-test element. The steady-state distribution was in agreement with existing re-solution and release models. The release of fission gas as a result of the transient was from the unrestructured and equiaxed regions, probably because of the additional thermally induced cracking produced by the transient.

2. The transient-induced swelling was estimated to be no greater than $0.15 \%$ (or $0.15 \mathrm{mil}$ ) on the radius, which is smaller than the error in fuel-cladding gap size.

3. The mechanisms proposed by Poeppel and Dias for a bimodal resolution model and by Gruber for a coalescence and migration model were found to apply. The surface-diffusion rate agreed with the observed bubblemigration rate of $\sim 4 \mathrm{\mu m} / \mathrm{sec}$ in the columnar region.

\section{ACKNOW LEDGMENTS}

We gratefully acknowledge the assistance of $E$. E. Gruber and R. B. Poeppel in the review of the manuscript. We also acknowledge the laser sampling performed by the Chemical Engineering Division, especially J. Williams, and the replica preparation performed by G. M. Dragel. 
REFERENCES

1. D. E. Rimmer and A. H. Cottrell, The Solution of Inert Gas Atoms in Metals, Phil. Mag. 2, 1345 (1957).

2. G. W. Johnson and R. Shuttleworth, The Solubizity of Krypton in Liquid Lead, Tin, and Silver, Phil. Mag. 4, 957 (1959).

3. A. D. Shapham, Electron Microscope Observations of the Fission-gas Bubble Distribution in UO2, Nuc1. App1. 2, 123 (1966).

4. A. M. Ross, Irradiation Behavior of Fission-gas Bubbles and Sintering Pores in UO2, J. Nucl. Mater. 30, 134 (1969).

5. S. R. Pati, M. J. Dapht, D. R. O'Boyle, and T. J. Patrician, Re-solutioncontrolled Eission-gas Behavior in UO 2 Irradiated in EBR-II, ANL-8003 (Aug 1973).

6. E. O. Ballard and M. K. Millholen, Proposal to Irradiate Unencapsulated Instrumented Fuel Pins in the EBR-II Subassembly PNL-17, BNWL-1420 (June 1970).

7. R. O. Meyer and B. J. Buescher, A Simple Method of Calculating the Radial Temperature Distribution in a Mixed-oxide Fuel Element, Nuc1. Tech. 14, 153-156 (1972).

8. A. B. Rothman, A. E. Wright, D. Stahl, and L. J. Harrison, First TREAT Mark-II Loop Failure Threshold Experiment with Preirradiated FFTF-Type Fuel (H3), Trans. Am. Nucl. Soc. 16, 181-182 (1973).

9. P. Roy1, A. Watanabe, and A. K. Agrawa1, "Transient Fue1-cladding Deformation Analysis of the In-pile H3 TREAT Test with the SAS2A/DEFORM-II Code," presented at Int. Conf. on Structural Mechanics in Reactor Technology, Berlin, Germany, Sept 1973, Paper No. C 3/1.

10. L. C. Michels and G. M. Drage1, Preparation of Replicas for EZectron Microscopy of Irradiated Cercmic Fuels, ANL-7790 (Apr 1971).

11. L. C. Michels, J. D. B. Lambert, I. A. Neimark, and G. M. Dragel, Reactor Development Progrom Progress Report: March 1971, ANL-7798, pp. 68-69 (Apr 19, 1971).

12. L. C. Michels and G. M. Drage1, Reactor Development Program Progress Report: November 1971, ANL-7887, p. 5.33 (Dec 29, 1971).

13. P. S. Maiya, Surface Diffusion, Surface Free Energy, and Grain-boundary Free Energy of Uranium Dioxide, J. Nuc1. Mater. 40(1), 57-65 (1971).

14. J. W. Harrison, An Extrapolated Equation of State for Xenon for Use in Fuel Swelling Calculations, J. Nucl. Mater. 31, 99-106 (1969).

15. C. E. Johnson, D. V. Steid1, and C. E. Crouthamel, "Distribution of Gaseous Fission Products in Irradiated Mixed-oxide Fuels," Proc. Conf. on Fast Reactor Fuel EZement Technology, ANS, New Orleans, La., Apr 1971, pp. 603-613.

16. J. D. B. Lambert, ANL, private communication (Sept 1973).

17. R. S. Nelson, The Stability of Gas Bubbles in an Irradiation Environment, J. Nuc1. Mater. 31, 153 (1969).

18. C. Ronchi and Hj. Matzke, CaZculations on the In-pile Behavior of Fission Gas in Oxide Fuels, EUR-4877E, Karlsruhe (1972). 
19. D. C. Bullington and G. E. Culley, Characterization of Intragranular Porosity Precipitated During a TREAT Transient Test of PNL-1-7 After Prior Irradiation in EBR-II, HEDL-TME 72-80 (June 1972).

20. R. S. Barnes and R. S. Nelson, "Theories of Swelling and Gas Retention in Reactor Materials," in Radiation Effects, Met. Soc. Conf. 37, 225-267 (Gordon and Breach, New York, 1967).

21. F. A. Nichols, Behavior of Gaseous Fission Products in Oxide Fuel Elements, Bettis Atomic Power Laboratory, WAPD-TM-570 (1966).

22. R. B. Poeppel and J. W. Dias, Effects of Bubble Size on Fission Gas Re-solution, Trans. Am. Nuc1. Soc. 17, 182-183 (1973).

23. E. E. Gruber, "Migration and Coalescence of Fission Gas Bubbles in Oxide Fuels by Surface Diffusion," Proc. Int. Conf. on Phys. Met. of Reactor Fuel Elements (Sept 1973), to be published; p. 7.1 in Reactor Development Program Progress Report: November 1973, ANL-RDP-22 (Jan 8, 1974).

24. G. E. Culley, J. E. Hanson, R. D. Leggett, and F. E. Bard, "Response of an EBR-II Irradiated, Mixed Oxide Fuel Pin to an Overpower Transient in TREAT," Proc. Conf. on Fast Reactor Fuel Element Technology, ANS, New Orleans, La., Apr 1971, pp. 657-678. 